\title{
Ação política na internet brasileira
}

Cláudio Luis de Camargo Penteado

Doutor em Ciência Política, Professor do Centro de Engenharia, Modelagem e Ciências Sociais Aplicadas da Universidade Federal do ABC (UFABC)

Marcelo Burgos Pimentel dos Santos

Doutorando em Ciência Políticas na Pontifícia Universidade Católica de São Paulo (PUC/SP)

Rafael Aguiar de Paula Araújo

Doutor em Ciência Política, Professor Pontifícia Universidade Católica de São Paulo (PUC/SP) e da Escola de Sociologia e Política

Sidney Jard da Silva

Doutor em Ciência Política, Professor do Centro de Engenharia, Modelagem e Ciências Sociais Aplicadas da Universidade Federal do ABC (UFABC)

O artigo analisa a produção acadêmica sobre as diversas formas de ação política na Internet brasileira. A partir da conceituação de ação política e sua adaptação para a web, o texto mostra as diferentes formas de participação política criadas e desenvolvidas no novo ambiente informacional, destacando a Internet como uma arena pública e um mecanismo para mobilização civil.

Palavras-chave: Tipologia; Ação política; Internet; NTICs; Brasil.

\section{Political Action in Brazilian Internet}

This article analyzes the academic literature on different forms of political action in Brazilian Internet. Analyzing the conceptualization of political action and its adaptation to the wWw, this work shows different ways of political participation developed by this new informational 
environment. It also highlights the Internet as a public arena and a mechanism for civil mobilization.

Keywords: Typology; Political action; Internet; NTICs; Brazil.

Recebido em 08.09.2010 Aceito em 10.01.2011

\section{Introdução}

O desenvolvimento das Novas Tecnologias de Informação e Comunicação (NTICs) incorporou diversas mudanças nos processos sociais, inserindo novas modalidades e práticas humanas que, atreladas às ferramentas de comunicação, produzem novas relações sociais. No campo político, concomitante com as práticas tradicionais, outras práticas e configurações estão surgindo, que amparadas nas NTICs, inserem novas formas de ação política.

Nessa nova conjuntura social, a Internet e seus dispositivos ganharam importante destaque, formatando novos mecanismos de interação via rede mundial de computadores, a world wide web (WWW). As características dessa rede impõem novas dinâmicas e possibilidades, com destaques para: a) velocidade na transmissão das informações; b) interatividade; e c) arquitetura de rede. Assim, a Internet, com suas características, introduz uma lógica comunicativa inovadora, produzindo novas modalidades de práticas políticas, assim como integra novos atores políticos em sua dinâmica.

Cabe ainda ressaltar duas importantes peculiaridades da Internet: a possibilidade de interatividade entre o emissor das mensagens e sua audiência e, ainda, a capacidade dos usuários da rede produzirem conteúdo. Essas características permitem que pessoas comuns possam entrar em contato direto com os representantes políticos (principalmente por e-mail), comentar as notícias publicadas (opção disponível nas versões on-line dos principais jornais e revistas), participar de chats com jornalistas e "especialistas", participar de grupos de discussão e criar suas próprias páginas pessoais, para divulgar suas ideias ou posições, como é o caso dos blogs.

As transformações, introduzidas pela Internet no jogo político, trouxeram duas posições principais. De um lado os (ciber) otimistas que, empolgados pelas possibilidades da rede, acreditam que é possível democratizar o acesso à informação e promover uma maior participação popular, inclusive, na vida política. Por outro lado, os (ciber) pessimistas defendem que a Internet somente cria novas formas de dominação e controle, que ao invés de promover a maior participação popular, ajuda a aumentar o fosso de exclusão social e política.

Contudo, como qualquer ferramenta, a Internet e seus dispositivos dependem do uso que as pessoas fazem deles. O potencial político e informacional fica limitado: (1) pelo número ainda reduzido de pessoas 
com acesso à rede e pela capacidade cognitiva dos usuários; (2) pela falta de cultura política participativa; e (3) pela lógica do espetáculo que domina os processos comunicacionais atuais, que não favorece a expansão ou qualidade do debate político, muito menos na práxis política.

Este artigo tem o objetivo de identificar as formas de ação política na Internet no Brasil, propondo uma tipologia dessas ações, ferramenta importante para o desenvolvimento de futuros estudos, assim como traz exemplos práticos para ilustrar as transformações que o uso da Internet traz também para a política contemporânea.

\section{Tipos de ação política na Internet}

Ao falar em ação política na Internet, busca-se entender as diferentes formas de exercício da política, não ficando limitada à noção da esfera estatal e institucional, mas, ampliando a concepção das diversas relações de poder criados e desenvolvidos na $w e b^{1}$.

Um dos primeiros autores a sistematizar a importância da Internet e o consequente poder que ela tem foi Pierre Levy (1999). Com uma visão otimista sobre a expansão das NTICs, o autor sinaliza que o desenvolvimento tecnológico possibilitou a formação do que ele vai chamar de cibercultura a partir de ações de jovens conectados à rede mundial de computadores, produzindo novas formas de experiências coletivas e um "saber virtual coletivo" (LEVY, 1999).

Ao pensar sobre as relações de poder no ciberespaço, aqui entendido como um campo de comunicação interativa e comunitária, o autor indica que a cibercultura é resultado de um movimento social que promove a "conjugação eficaz das inteligências e das imaginações humanas" (LEVY, 1999, p. 199). O ciberespaço insere uma nova lógica comunicativa alternativa às mídias de massa tradicionais, pois permitem que os indivíduos utilizem o espaço para encontrar as informações que desejam, assim como, também, difundir sua "versão dos fatos". Ainda para esse autor, o ciberespaço, por suas características técnicas, não possui território físico, o que enfraquece o poder do Estado-nação, o qual é solidificado no controle do território. A atuação no espaço virtual desterritorializado da Internet rompe com as fronteiras e controles do Estado, criando novos conflitos regulatórios (regulamentação das transações financeiras, direitos autorais, propaganda política, etc).

Mesmo tendo uma posição favorável quanto ao potencial democrático das NTICs, principalmente da internet, o autor alerta que não se deve confundir o uso das ferramentas do ciberespaço com a democracia. O uso da rede para divulgação de propagandas governamentais, anúncio dos endereços de líderes políticos, organização de referendos e outras formas instrumentais, são apenas mecanismos de atualização das antigas práticas políticas, que em nada mantém relação com a cibercultura. Levy (1999) defende que a cibercultura pode

A ideia de poder está relacionada com o exercício da dominação, isto é, "a probabilidade de encontrar obediência a uma ordem" (WEBER, 1999, p. 33). 
desenvolver uma nova concepção de democracia, que vai além do uso técnico das ferramentas, e criar novas práticas democráticas, estruturadas dentro do potencial de inteligência coletiva, como, por exemplo, a autoorganização das comunidades por meio de comunicação interativa ou a avaliação direta das políticas públicas pelos cidadãos, por meio do ciberespaço. Em sua perspectiva otimista, indica que a política, na Internet, resultaria de uma transformação cultural que, por meio dessa cultura interativa e participativa, ampliaria a democracia.

Em uma visão sociológica, Manuel Castells desenvolve importantes reflexões sobre a Internet. $O$ autor espanhol sinaliza que estamos assistindo o nascimento de uma nova cultura: a cultura da virtualidade real. Segundo Castells (1999a), o desenvolvimento das NTICs possibilita que o virtual, produzido e transmitido no meio midiático, seja compreendido como "real" pela audiência, isto é, as mensagens produzidas no campo midiático ganham o status de "realidade" para uma grande parcela da população.

Castells (1999a), assim como Pierre Levy, também sinaliza que o Estado-nação está com sua capacidade de intervenção comprometida pela desterritorialização gerada pelo desenvolvimento das NTICs, criando novas demandas e práticas que se organizam e se desenvolvem por meio de fluxos. Nessa nova formatação, novas formas de articulação políticas vão surgir por meio do uso dessas ferramentas, em destaque a Internet, restando aos Estados saberem adequar-se à nova realidade globalizada e informacional.

O autor sinaliza o surgimento de uma "política informacional", estruturada pelo uso intensivo dos meios de comunicação. A política informacional de Castells (1999b) cria novas regras para o jogo político, atuando dentro do contexto da sociedade em rede. Nessa nova conjuntura, a mídia eletrônica (em especial a Internet) se torna um "espaço privilegiado da política". Para Castells (1999b, p. 367), "sem a mídia, não há meios de adquirir ou exercer poder".

A política desenvolvida no espaço da mídia faz com que seu campo simbólico se torne uma área de batalha da política contemporânea, na qual as forças políticas buscam construir suas representações e defender seus interesses. Essa nova característica faz com que a política (informacional) ganhe característica de espetacularização, ou, nos próprios termos de Castells, a "política do showbiz", calcada pelo uso do espetáculo político, em detrimento do debate político. O autor destaca que esse novo formato propicia o desenvolvimento de uma política do escândalo ${ }^{2}$, o que acaba por enfraquecer a imagem da política, principalmente dos políticos e dos partidos políticos, como uma atividade cidadã, favorecendo a personalização da política, característica comum na política sul-americana.

Castells (1999b) afirma que a comunicação eletrônica pode aprimorar formas de participação política e comunicação horizontal entre os cidadãos e, por outro lado, pode, também, fortalecer a política do

Para saber mais, ler Thompson (2002). 
showbiz e exaltar a individualização da política e da sociedade. Situações essas que colocam em cheque a noção de democracia liberal clássica, apontando para a formatação de um novo formato de democracia: a democracia informacional, estruturada nos fluxos de comunicação da sociedade em rede.

No Brasil, o tema Internet e política vêm atraindo muitos pesquisadores, principalmente os mais jovens. Gomes e Maia (2008), em suas reflexões sobre comunicação e democracia, identificam 3 matrizes teóricas que orientam os estudos nesse campo. A primeira é a abordagem da tradição liberal, que tem como preocupação central a autonomia privada dos cidadãos, agrupando em sua agenda reforço e defesa dos direitos individuais. Nessa abordagem, prevalece uma linha de investigação que privilegia a avaliação do papel dos meios de comunicação, na defesa dos direitos e liberdades dos indivíduos (direito de expressão, vigilância do Estado etc).

A segunda matriz teórica está ancorada nos pressupostos da tradição republicana, a qual tem como tema central a garantia e o exercício da cidadania. A preocupação encontra-se em descobrir meios para garantir o controle da sociedade civil sobre o Estado. Os estudos são voltados para as oportunidades de participação política e engajamento na vida coletiva: a criação de um ethos participativo e a participação e o engajamento político.

A última linha teórica os autores a identificam como abordagem deliberacionista. Essa linha começou a ganhar corpo nos anos 90, como uma alternativa aos modelos liberal e republicano. Com forte influência da teoria discursiva de Habermas, a preocupação central dessa abordagem é garantir a "existência de uma arena discursiva que funciona como esfera intermediária entre o Estado e a sociedade" (GOMES; MAIA, 2008, p. 16). Nesse sentido, as pesquisas dentro desta matriz têm como finalidade verificar se os cidadãos têm a capacidade e oportunidade de deliberar racionalmente e publicamente sobre decisões coletivas.

Gomes e Maia (2008) sinalizam que, por si só, a Internet não pode ser considerada uma ferramenta de promoção da democracia ou em esfera pública virtual, por dois aspectos: (1) os dispositivos de comunicação, que permitem novas modalidades de comunicação descentralizadas, também podem favorecer formas antidemocráticas de ação política; e (2) o fortalecimento da democracia não passa apenas por estruturas comunicativas eficientes, mas, também, pelo engajamento dos cidadãos nos debates públicos.

Esses autores concluem que as ferramentas tecnológicas, assim como a Internet e seus dispositivos de comunicação, disponibilizam para os atores políticos, instrumentos de comunicação política, mas os seus resultados dependem dos usos que são feitos de seus canais de comunicação. A ação política está diretamente relacionada com o potencial do ator político, não somente com o mecanismo de comunicação. Diante desse quadro, sustentam que é necessário "manobrar socialmente as ferramentas da rede para que suas 
possibilidades se transformem em oportunidades democráticas" (GOMES; MAIA, 2008, p. 325).

Atentos à advertência de Gomes e Maia (2008), de considerar a Internet como uma ferramenta com potencial político, no qual os atores sociais podem utilizar seus recursos para desenvolver diferentes ações políticas e não como um campo de realização democrático, abaixo será exposta uma tipologia de classificação das formas de ação política existentes na e pela Internet.

A tipologia foi construída visando atender às 3 grandes matrizes teóricas que estudam a relação entre política e Internet: a matriz liberal, republicana e deliberativa. Desta forma, a classificação procura acolher essas abordagens, agrupando em 5 tipos de ação política: a) informações políticas; b) governo eletrônico; c) esfera pública; d) (ciber)ativismo; e e) comunicação política.

\section{Por uma tipologia da ação política na Internet}

\subsection{Informações políticas}

A Internet, por suas características tecnológicas, é caracterizada pela fluidez e polissemia no fluxo das informações. O potencial comunicativo da web possibilita a rápida circulação de informações, bem como possibilita que os usuários produzam suas próprias informações, quebrando o sistema unidirecional - verticalizado - típico da comunicação de massa. Outro elemento comunicacional importante é a possibilidade de interação entre o produtor da informação e o receptor, o que estabelece novas modalidades de comunicação mais participativas. É por meio da informação que os cidadãos obtêm conhecimento sobre os acontecimentos e formam sua opinião, que vão orientar sua conduta política. Os cidadãos também podem utilizar as avaliações, análises e críticas reproduzidas nos veículos de informação. Essas leituras são importantes elementos que podem exercer influência na formação da opinião pública, principalmente porque servem de "atalhos informacionais", pelos quais os cidadãos comuns, que geralmente não têm muito conhecimento sobre temas políticos, possam conseguir interpretar a realidade política e orientar suas práticas. São exemplos de ação política na internet, por meio de informações políticas:

Portais de Internet: sites que disponibilizam informações da política nacional e internacional de diversas fontes de notícias, inclusive com a produção de conteúdo próprio de informações. As informações políticas concorrem com notícias de assuntos gerais na página principal dos portais, mas, geralmente, possuem seções específicas dentro do portal. As notícias políticas que se encaixam aos critérios de noticiabilidade do jornalismo ganham visibilidade dentro dos portais. Os portais destacam-se no Brasil, por atrair um grande número de internautas. Essa característica permite que as informações políticas divulgadas, principalmente em suas páginas principais, tenham maior acessibilidade. 
Exemplos de portais brasileiros:

- Globo.com: Portal ligado às Organizações Globo, principal grupo de mídia brasileiro: Disponível em: <http://www.globo.com/>. Acesso em: 03 out. 2008.

- Internet Group (iG): Portal do grupo BrasilTelecom. Notabilizou-se, por prover acesso discado à internet de forma gratuita: Disponível em: <http://www.ig.com.br/>. Acesso em: 04 out. 2008.

- MSN Brasil: Portal ligado ao grupo Microsoft: Disponível em: $<$ http://br.msn.com/>. Acesso em: 05 out. 2008.

- Terra: Portal ligado ao grupo espanhol Telefônica: Disponível em: <http://www.terra.com.br/portal/>. Acesso em: 05 out. 2008.

- UOL: Portal ligado ao Grupo Folha (importante grupo de mídia brasileiro) - Portugal Telecon: Disponível em: <http://www.uol.com.br/>. Acesso em: 06 out. 2008.

- Yahoo: Portal ligado à empresa norte-americana YAHOO!: Disponível em: <http://br.yahoo.com/>. Acesso em: 06 out. 2008.

Sites da mídia tradicional: homepages de empresas da imprensa tradicional. Esses sites se caracterizam por reproduzir o conteúdo publicado em suas versões originais (algumas apresentam restrições de acesso a algumas informações), além de disponibilizar a possibilidade de consultar arquivos. O formato e o conteúdo seguem a linha editorial já existente da empresa. Assim como os portais, as principais empresas de comunicação operam dentro da lógica midiática, destacando as informações com maior apelo junto ao leitor/ audiência. Sites de mídia tradicionais mais famosos garantem um maior número de acesso, assim como garantem maior credibilidade. É importante destacar que no Brasil, existem empresas de alcance nacional, regional e local e, essa diferenciação, reflete no tipo de informações políticas divulgadas, uma vez que empresas de alcance nacional tendem a dar maior destaque às notícias políticas nacionais e internacionais, enquanto que as empresas locais geralmente reproduzem material de outras agências em relação aos assuntos da política nacional e internacional, dando maior destaque para a cobertura dos assuntos da política local.

Exemplos:

- Grupo Abril: responsável pela principal revista semanal brasileira - Veja (Veja.com): Disponível em: $<$ http://veja.abril.com.br/index.shtml>. Acesso em: 10 out. 2008.

- Grupo Estado: responsável por um dos jornais de maior circulação no país, ligado ao Portal Terra - O Estado de São 
Paulo (Estadao.com): Disponível em: <http://www.estadao.com.br/home/index.shtm>. Acesso em: 11 out. 2008.

- Grupo Folha: responsável pelo jornal de maior circulação no país, ligado ao Portal UOL - Folha de São Paulo (Folha Online): Disponível em: <http://www.folha.uol.com.br/>. Acesso em: 12 out. 2008.

- Rede Globo: Rede de comunicação mais poderosa e importante no Brasil, localizado no Portal Globo.com: Disponível em: <http://redeglobo.globo.com/>. Acesso em: 13 out. 2008.

Sites de Política: voltados exclusivamente para a divulgação de informações políticas e debate sobre os temas abordados. Geralmente, esses sites possuem um posicionamento político que influencia na disponibilização de informações. Como os temas políticos não despertam a atenção do brasileiro comum, esses sites têm pouca acessibilidade. Por outro lado, por agregarem posicionamentos políticos, esses espaços têm um público "fiel". Ao contrário do que acontece nos EUA, os sites brasileiros de política não tem grande influência no debate político e na agenda da mídia. Exemplos:

- Política para Políticos: site apartidário voltado para quem têm funções públicas. Disponível em: $<$ http://www.politicaparapoliticos.com.br/capa.php $>$. Acesso em: 25 out. 2008.

- Congresso em Foco: site voltado para os assuntos e notícias do Congresso Nacional. Disponível em: $<$ http://congressoemfoco.ig.com.br/>. Acesso em: 25 out. 2008.

- ABC Politiko: site com informações e análises sobre a política brasileira Disponível em: <http://www.abcpolitiko.com.br/>. Acesso em: 27 out. 2008.

Blogs de Política: em umformato mais simples e interativo, os blogs de política são espaços para a divulgação de informações políticas, geralmente produzidas em outras fontes, mas, também, podem conter notícias postadas pelo próprio blog. É comum a circulação de informações dos bastidores da política e repercussão de assuntos polêmicos. O destaque são os fóruns de debate, nos quais os leitores podem comentar as notícias produzidas. No Brasil, os blogs de política mais acessados são os escritos por jornalistas já conhecidos da grande mídia, que utilizam o formato para ter mais liberdade na atividade (Penteado; Santos; Araújo, 2008). Esses blogs seguem o estilo do jornalismo tradicional, principalmente na formatação dos textos. Mas, também existem blogs de política escritos por cidadãos comuns, alguns anônimos, assim como coletivos de blogs, que repercutem informações políticas. Os blogs mais 
acessados no Brasil estão vinculados às empresas de mídia tradicional ou a um grande Portal. Exemplos:

- Blog dos Blogs: escrito pelo jornalista Tales Faria, editor-chefe do Jornal do Brasil, localizado no portal do iG. Disponível em: $<$ http://colunistas.ig.com.br/blogdosblogs/>. Acesso em: 02 nov. 2008.

- Blog do Noblat: principal blog de política brasileiro, escrito pelo jornalista Ricardo Noblat. Localizado no site do Jornal 0 Globo.

em: <http://oglobo.globo.com/pais/noblat/>. Acesso em: 02 nov. 2008.

- Josias de Souza: escrito pelo jornalista Josias de Souza, colunista da Folha de São Paulo. Localizado nos blogs da Folha. Disponível em: $<$ http://josiasdesouza.folha.blog.uol.com.br/>. Acesso em: 04 nov. 2008.

- Luis Nassif Online: escrito pelo jornalista Luis Nassif. Localizado no Portal do iG. Disponível em: $<$ http://projetobr.com.br/web/blog/5 $>$. Acesso em: 05 nov. 2008.

- Blog Reinaldo Azevedo: escrito pelo jornalista Reinaldo de Azevedo, colunista da Revista Veja. Localizado no site veja.com. Disponível em: $<$ http://veja.abril.com.br/blogs/reinaldo/>. Acesso em: 11 nov. 2008.

\subsection{Governo eletrônico}

Abrange diversas ações governamentais que utilizam meios eletrônicos (que vão além da Internet) para a realização de diversas tarefas. A área envolve diversas linhas de pesquisa que possuem diferentes leituras e interpretações sobre a definição de governo eletrônico ou e-gov. Para efeito desta pesquisa, adotamos a concepção de Gouveia (2004), que entende como o uso das tecnologias de comunicação e informação pela administração pública para o gerenciamento de tarefas, organização e prestação de serviços ao cidadão, bem como para a realização de suas atividades fins, de forma a potencializar a operacionalização de políticas públicas de forma eficaz, eficiente e com menor custo. São funções do governo eletrônico: prestação eletrônica de informações e serviços; regulamentação das redes de informação, governança, certificação e tributação; prestação de contas públicas, transparência e monitoramento da execução orçamentária; ensino à distância; difusão cultural; e-procurement (aquisição de bens e serviços pela Internet, exemplo: pregão eletrônico), de forma a garantir maior publicidade nas contratações e compras do poder público; e estímulo ao e-commerce, principalmente para as pequenas e médias empresas 
(FERNANDES, 2000). O governo eletrônico na web está associado à promoção de atividades institucionais de órgãos públicos, garantindo maior transparência nos processos, disponibilizando informações da administração pública, incrementando as facilidades para os cidadãos utilizarem os serviços públicos e criando espaços para debate sobre assuntos de interesse público, como o orçamento ou novas legislações. Outra função verificada no governo eletrônico é a comunicação política, com a divulgação de informações de interesse da administração pública, que vai desde a agenda das autoridades e dos órgãos públicos, até a publicidade de novas legislações e políticas públicas. São exemplos de ação política na Internet, por meio do governo eletrônico:

a) Portais do Governo Federal: sites ligados aos órgãos da administração pública federal, vinculados aos poderes Executivo, Legislativo e Judiciário. Os órgãos do poder Executivo vão desde o Portal oficial do Governo Brasileiro, passando pelos Ministérios e chegando até as autarquias. No Legislativo, na esfera federal, são os sites do Senado e da Câmara dos Deputados $^{3}$. E, em relação ao Judiciário, são os sites do Supremo Tribunal Federal, Conselho Nacional de Justiça, Superior Tribuna de Justiça e Tribunais Regionais Federais ${ }^{4}$. Exemplos:

- Portal do Governo Brasileiro: site oficial da República Federativa do Brasil. Disponível em: <http://www.brasil.gov.br/>. Acesso em: 08 nov. 2008.

- Portal do Ministério de Ciência e Tecnologia. Disponível em: <http://www.mct.gov.br/>. Acesso em: 08 nov. 2008.

- Portal Anatel: site da Agência Nacional de Telecomunicações, responsável pela regulação do setor. Disponível em: < http://www.anatel.gov.br/Portal/exibirPortalinternet.do $>$. Acesso em: 09 nov. 2008.

- Portal da Câmara dos Deputados. Disponível em: <http://www2.camara.gov.br/>. Acesso em: 09 nov. 2008.

- Senado Federal. Disponível em: <http://www.senado.gov.br/sf/>. Acesso em: 09 nov. 2008.

- STF: site do Supremo Tribunal Federal. Disponível em: $<$ http://www.stf.jus.br/portal/principal/principal.asp $>$. Acesso em: 12 nov. 2008.

- CNJ: site do Conselho Nacional de Justiça. Disponível em: <http://www.cnj.gov.br/>. Acesso em: 12 nov. 2008.

b)Portais dos Governos Estaduais: sites ligados aos órgãos da administração pública estadual, atrelados aos poderes Executivo, Legislativo e Judiciário, em escala estadual. Reprodução no âmbito

Aqui é possível seguir ao vivo o funcionamento tanto do Senado Federal como da Câmara dos Deputados, assistindo aos debates, discursos na tribuna e acompanhando CPIs, ..

No Brasil, é possível fazer o acompanhamento on line de processos em tramitação na Justiça. 
regional dos sites oficiais dos três poderes. Cabe aqui destacar que no Brasil, por haver enormes desigualdades regionais, pode-se perceber uma grande variação da diferença da prestação de serviços e mesmo da qualidade técnica dos portais de estado para estado. De acordo com o regime federativo brasileiro, diversas atribuições públicas são de responsabilidade da esfera estatal, com destaque para a Segurança Pública. Exemplos:

- Portal do Governo do Estado de São Paulo: Disponível em: $<$ http://www.saopaulo.sp.gov.br/>. Acesso em: 13 nov. 2008.

- Portal Oficial do Governo do Estado do Amazonas: Disponível em: <http://www.amazonas.am.gov.br/>. Acesso em: 13 nov. 2008.

- Assembleia Legislativa do Estado de São Paulo: Disponível em: <http://www.al.sp.gov.br/portal/site/Internet/>. Acesso em: 13 nov. 2008.

- Assembleia Legislativa do Estado do Rio de Janeiro: Disponível em: <http://www.alerj.rj.gov.br/>. Acesso em: 13 nov. 2008.

- Tribunal de Justiça do Estado de São Paulo: Disponível em: <http://www.tj.sp.gov.br/>. Acesso em: 13 nov. 2008.

- SSP - Secretaria do Estado de Segurança Pública do Estado de São Paulo: Disponível em: $<$ http://www.ssp.sp.gov.br/home/>. Acesso em: 13 nov. 2008.

c)Portais dos Governos Municipais: sites ligados aos órgãos da administração pública municipal, vinculados aos poderes Executivo e Legislativo. No Brasil, ainda existem diversos municípios que não contam com sites oficiais, tanto do poder Executivo como Legislativo. As principais cidades possuem sites com diversos serviços para os cidadãos, existindo grande variação de cidade para cidade. O destaque fica para a utilização dos sites principalmente para a divulgação do turismo e arrecadação de impostos. Mas, de forma geral, os sites municipais servem para a reprodução de informações como endereços, telefones e horários. Exemplos:

- Portal da Prefeitura da Cidade de São Paulo: Disponível em: $<$ http://www.capital.sp.gov.br/portalpmsp/homec.jsp>. Acesso em: 18 nov. 2008.

- Portal Salvador: site oficial do município de Salvador/BA. Disponível em: <http://www.pms.ba.gov.br/>. Acesso em: 18 nov. 2008.

- Câmara Municipal de São Paulo: Disponível em: $<$ http://www.camara.sp.gov.br/cr0309 net/forms/frmPrincipa l.aspx>. Acesso em: 18 nov. 2008.

- Tribunal de Contas do Município de São Paulo: Disponível em: <http://www.tcm.sp.gov.br/>. Acesso em: 18 nov. 2008. 
d)Sites de órgãos públicos: diversos órgãos da administração pública estão disponibilizando diversos serviços por meio da Internet, de forma a agilizar e desburocratizar seus processos administrativos. Por exemplo, podemos citar o caso da Agência de fomento para pesquisa do Estado de São Paulo, a FAPESP, que realiza todos os procedimentos de concessão de benefícios a pesquisadores (bolsas, auxílios, diárias, etc) por meio eletrônico, através de um sistema chamado Sage. No âmbito federal, destaque para o site do Conselho Nacional de Desenvolvimento Científico e Tecnológico (CNPq), no qual está disponibilizada a Plataforma Lattes, onde os pesquisadores brasileiros registram seu currículo acadêmico, servindo de fonte de dados padrão para a vida acadêmica. Por fim, cabe destacar o programa ReceitaNet, desenvolvido pela Secretaria da Receita Federal em 1996, para facilitar e agilizar o processo de declaração de imposto de renda anual. Exemplos:

- CNPq: Disponível em: <http://www.cnpq.br/>. Acesso em: 20 ago. 2008; e Plataforma Lattes: Disponível em: $<$ http://lattes.cnpq.br/>. Acesso em: 20 ago. 2008.

- FAPESP: Disponível em: <http://www.fapesp.br/>. Acesso em: 20 ago. 2008; e Sage: Disponível em: <http://www.fapesp.br/sage/>. Acesso em: 20 ago. 2008.

- Receita Federal: Disponível em: $<$ http://www.receita.fazenda.gov.br/>. Acesso em: 20 ago. 2008.

- Receitanet: Disponível em: <http://www.receita.fazenda.gov.br/PessoaFisica/ReceitaNet/ default.htm >. Acesso em: 21 ago. 2008

\subsection{Esfera pública}

É associada à visão deliberacionista de democracia, que vê na prática do debate político um mecanismo de promoção da democracia, onde os cidadãos participam ativamente da discussão dos assuntos políticos. A Internet tem a possibilidade de criar mecanismos de viabilidade da constituição de uma esfera pública de discussão política. Esse tema tem grande presença na obra de Gomes e Maia (2008), que sustentam que a Internet reduz os custos da participação política e permite a interação de diversos parceiros através dos mecanismos de comunicação da rede. Segundo os autores, suas ferramentas possibilitam a criação de plataformas de participação política para além dos meios tradicionais, no Brasil. Contudo, advertem que ela não pode ser considerada como uma esfera pública no sentido habermasiano, no sentido de promoção de um debate entre argumentos racionais, mas pode criar outro sentido de "esfera pública", de maneira a criar espaços para a discussão pública. Gomes e Maia (2008) argumentam que a Internet se consolida como uma importante "arena conversacional", na qual podem ser geradas discussões políticas, onde diferentes pessoas possam participar/ interagir, através dos mecanismos técnicos, rompendo com a 
questão do compartilhamento do espaço e estabelecendo conexões em forma de rede. A Internet tem a possibilidade de expandir os fóruns de debates públicos, entretanto, o acesso a esses fóruns é limitado, tanto por parte daqueles que não tem acesso a Internet ou não sabem lidar com essa tecnologia, bem como de cidadãos que não tem interesse em participar (a principal barreira para a promoção da democracia via web, segundo os autores). Outra preocupação diz respeito à qualidade do debate nos espaços de discussão pública da rede, uma vez que os participantes dessas discussões expressam suas opiniões pessoais sem vincular a apresentação de argumentos racionais, negando os princípios da prática argumentativa, o que pode levar ao desenvolvimento de práticas antidemocráticas, mas que também se configuram como formas de ação política. São exemplos de ação política na Internet por meio da constituição de esfera pública:

a)Grupos ou listas de discussão: diversas pessoas se organizam, formando grupos de discussão, seja por meio de um provedor comum ou por uma lista de e-mails, para discutirem variados assuntos, entre eles, temas políticos. Essas discussões geralmente são fechadas em grupos pequenos, o que restringe a abrangência do debate e sua repercussão. Podem-se notar dois tipos de comportamento: um mais comum, no qual todos comungam de posições políticas semelhantes e o debate serve para reforçar seus posicionamentos; o outro comportamento está voltado para o enfrentamento de posições antagônicas que, caso sejam muito acirradas, levam, invariavelmente, ao fim do grupo. Exemplos:

- LES - grupo de discussão sobre questões lésbicas: site de discussão política sobre ações ligadas ao grupo de lésbicas no Brasil. Disponível em: <http://www.lespt.org/>. Acesso em: 24 ago. 2008.

- Frutos do Brasil - Juventude em debate: grupo localizado no Google Groups, com 111 membros. Disponível em: <http://groups.google.com.br/group/frutosdobrasil?lnk>. Acesso em: 24 ago. 2008.

- Cidadania Brasil: grupo localizado no Yahoo! Grupos, com 2967 membros. Disponível em: $<$ http://br.groups.yahoo.com/group/cidadania_Brasil/?v=1\&t $=$ search \&ch $=$ web $\&$ pub $=$ groups $\& s e c=$ group $\&$ slk $=4>$. Acesso em: 24 ago. 2008.

b)Chats: diversos portais brasileiros e internacionais disponibilizam o serviço de chats, muitos deles são temáticos, o que, de certa forma, seleciona os participantes. Nos chats, diversos usuários usam o formato para expressar seu ponto de vista, o que promove um debate entre posições diferenciadas e com pontos de vista muitas vezes conflitante. Normalmente, as discussões nos chats são limitadas a um breve período de tempo, o que restringe a entrada de novos participantes e novas 
informações. No Brasil, os chats com temas políticos são raros (prevalece chats de assuntos de entretenimento e paquera), o que demonstra a apatia política do cidadão brasileiro, limitando o potencial discursivo e interativo desse mecanismo. Normalmente, no período eleitoral ou de um escândalo político, os chats discutem mais temas políticos, ampliando o debate e criando novos espaços de ação política. Exemplos:

- Chat com o candidato Almeida Lima (prefeitura de Aracajú, 2008) Disponível

em:

<http://www.infonet.com.br/politica/ler.asp?id=76571\&titulo

=politicaeeconomia $>$. Acesso em: 20 jul. 2008 .

- Notícia sobre Chat com os candidatos a prefeito de Joinvile (2008) - Disponível em: <http://www.clicrbs.com.br/anoticia/jsp/default.jsp?uf=2\&loc al=18\&section =Pol\%C3\%ADtica\&newsID =a2246123.xml> . Acesso em: 20 jul. 2008.

- Psicologia na política é tema de chat no Portal Amazônia Disponível em: $<$ http://www.clicrbs.com.br/anoticia/jsp/default.jsp?uf=2\&loc al=18\&section $=$ Pol\%C3\%ADtica\&newsID =a2246123.xml > . Acesso em: 17 jul. 2008.

- Documento com transcrição sobre Chat de política: Disponível em:

<http://www.interagir.org.br/politica/boletim/arquivos/1chatle itoreseditado.pdf>. Acesso em: 17 jul. 2008.

- Notícia sobre Chat para discutir a crise financeira mundial Disponível em: <http://blogs.diariodepernambuco.com.br/politica/?p=1314>. Acesso em: 22 jul. 2008.

c)Comunidades virtuais: agrupam usuários com identidade social comum, na qual discutem assuntos de interesse de todos. Nesses locais, dificilmente existirá um amplo debate com posições contraditórias. Seus fóruns são formados por pessoas que compartilham o mesmo ideal ou visão política, o que restringe o debate político. No Brasil, o destaque fica por conta da comunidade do Orkut que, segundo pesquisa de Barros Filho, Coutinho e Safatle (2007), chegou a criar 118 comunidades relacionadas com os principais candidatos a presidência em 2006 (Lula e Alckmin), favoráveis e contrárias, agregando mais de mil integrantes em algumas comunidades. No total das comunidades investigadas, foram mais de 1.531 .000 integrantes no período eleitoral, o equivalente a $1,5 \%$ dos eleitores que votaram no $2^{\circ}$. turno. Os mesmos autores informam que a dinâmica dessas comunidades eram mais utilizadas como fonte de afirmação a uma postura previamente definida, do que para a prática de debate político ou mesmo esclarecimento sobre programas de governo, funcionando, muitas vezes, para expressão de ataques pessoais à figura dos candidatos, inclusive com manifestações preconceituosas e disseminação de boatos. Exemplos: 
- Comunidade do Orkut: Repúdio a ignorância política - 58.044 membros

$<$ http://www.orkut.com.br/Main\#Community.aspx?cmm =207 8498 >. Acesso em: 24 out. 2008.

- Comunidade do Orkut: Eu odeio a política do Brasil - 14.971 membros $<$ http://www.orkut.com.br/Main\#Community.aspx?cmm $=152$ 8424>. Acesso em: 24 out. 2008.

- Comunidade do Orkut: Eu gosto de política!!! - 12.305 membros $<$ http://www.orkut.com.br/Main\#Community.aspx?cmm=649 396>. Acesso em: 24 out. 2008.

- Comunidade de Direitos Humanos: Disponível em: $<$ http://stoa.usp.br/direitoshumanos/profile/>. Acesso em: 24 out. 2008.

d)Blogs: com formatação mais simples e de fácil operação, o destaque fica por conta da formação de fóruns de debate a partir das informações postadas na seção principal do site. Em outro artigo (PENTEADO; SANTOS; ARAÚJO, 2008), apresenta-se que os blogs de política variam sua atuação de acordo com o perfil do blogueiro, o que também repercute nos fóruns. Os mais populares são os blogs escritos por jornalistas da grande mídia, que utilizam o espaço para divulgar informações de bastidores e apresentar suas análises. Esses blogs são mais acessados e têm maior credibilidade, o que possibilita um debate mais amplo, com a presença de leitores com diferentes posições políticas. Em outra pesquisa, sobre a cobertura dos blogs na eleição presidência de 2006 (PENTEADO; SANTOS; ARAÚJO, 2007), verificou-se que o debate nos fóruns dos blogs estudados ficou marcado pela baixa qualidade da argumentação e pela troca de ofensas entre os participantes, inclusive tendo sido verificado a exclusão de comentários devido a seu conteúdo. Os fóruns de blogs de política escritos por políticos, acadêmicos ou pessoas anônimas (independentes) se configuram pela existência de concordância, na grande maioria dos casos, com o posicionamento do autor, o que limita o debate. Exemplos: exemplos de blogs sobre política já foram listados acima (blogs de política como informação política), revelando a dupla potencialidade dos blogs: informação política e espaço de discussão política (esfera pública de debate).

\section{4 (Ciber)ativismo}

A Internet, por sua arquitetura em rede, possibilita o uso de seus canais para a ação política de associações cívicas. Segundo Gomes e Maia (2008), as NTICs permitem que grupos cívicos atuem sobre a sociedade civil de forma a promover habilidades políticas e cultivar virtudes cívicas por parte dos cidadãos. A tecnologia de comunicação da web serve de 
suporte para criar redes de articulação, divulgação e mobilização política de cidadãos em diversas partes do globo. Assim, diversos grupos de interesse político utilizam o potencial da Internet para realizar variadas formas de ação política, criando conexões entre os participantes. São exemplos de ação política de (ciber)ativismo:

Sites de Associações Cívicas: diversas entidades cívicas utilizam sites para divulgar suas propostas, informações sobre seu funcionamento, endereços e telefones de contatos, cadastro de participantes e membros, divulgação de eventos e atividades, mobilização e debate. Sua acessibilidade está relacionada com a própria imagem da entidade, geralmente construída fora da $w e b$. Pode ser uma importante ferramenta para a divulgação e publicidade. Seu alcance está restrito a um público de pessoas que se identificam com as atividades desenvolvidas pela entidade. Exemplos:

- Voto Consciente: associação cívica apartidária voltada para acompanhar a atuação dos parlamentares. Disponível em: $<$ http://www.votoconsciente.org.br/>. Acesso em: 18 out. 2008.

- Transparência Brasil: associação cívica voltada para o combate à corrupção, através da visibilidade dos gastos públicos. Disponível $<$ http://www.transparencia.org.br/index.html $>$. Acesso em: 18 out. 2008.

- Instituto Paulo Freire: associação cívica voltada para a promoção da cidadania. Disponível em: $<$ http://www.paulofreire.org/Capa/WebHome $>$. Acesso em: 18 out. 2008.

a) Sites de Movimentos Sociais: funciona nos moldes dos sites de associações cívicas, atraindo para seu endereço pessoas com simpatia pelas causas defendidas. Os mais acessados são movimentos com melhor articulação e maior visibilidade. Os sites também podem funcionar como uma ferramenta de organização e gestão em rede, principalmente para movimentos que atuam em diferentes localidades, como é o caso dos movimentos sociais ambientais. Cada movimento social possui uma particularidade, variando de acordo com seu campo de atuação, o que também pode influenciar na formação de seu site. Os sites são importantes ferramentas para divulgação da causa defendida e ganhar visibilidade, uma vez que a maioria dos movimentos sociais encontra pouco espaço para a divulgação de suas ideias, propostas e ações na mídia tradicional. Utiliza-se de diversas ferramentas: chats, e-mails, listas de discussão, vídeos, etc. Exemplos:

- Movimento dos Trabalhadores Rurais Sem-Terra (MST): luta pela reforma agrária. Disponível em: 
<http://www.mst.org.br/mst/home.php>. Acesso em: 28 out. 2008.

- Afrobras: movimento social de defesa dos direitos dos afrodescendentes, que luta pela inclusão social através da educação. Disponível em: < http://www2.afrobras.org.br/>. Acesso em: 28 out. 2008.

- SOS Mata Atlântica: movimento ambientalista de preservação e conservação da mata atlântica. Disponível em: $<$ http://www.sosmatatlantica.org.br/index.php $>$. Acesso em: 28 out. 2008.

- Movimento Sindical: divulgação e organização sindical. Disponível em: <http://www.sindicato.com.br/>. Acesso em: 28 out. 2008.

b) Blogs de Ativismo: pela facilidade e agilidade do formato, os blogs estão ganhando espaço como instrumento de ativismo no ciberespaço. Grupos de ativistas utilizam o template para realizar debates e promover ações. Geralmente os blogs de ativismo são voltados para objetos específicos, segmentando seu público e os acessos. São caracterizados por defenderem posições consideradas mais radicais. Podem utilizar o blog como espaço de discussão e articulação para o desenvolvimento de ações políticas. Sua credibilidade está limitada às pessoas que defendem a mesma causa. Por utilizarem o ciberespaço como ponto de encontro, suas ações políticas estão associadas às intervenções que muitas vezes acontecem dentro do universo digital das NTICs. Exemplos:

- Sérgio Amadeu: defesa dos softwares livres. Disponível em: <http://samadeu.blogspot.com/>. Acesso em: 24 out. 2008.

- Manual prático de delinquência juvenil: blog jovem de ativismo contra-cultural. Disponível em: $<$ http://www.delinquente.blogger.com.br/>. Acesso em: 24 out. 2008.

- Mundo em Movimentos: blogs sobre movimentos sociais. Disponível

em: $<$ http://mundoemmovimentos.blogspot.com/>. Acesso em: 24 out. 2008.

- Bodega Cultural: Disponível em: $<$ http://www.bodegacultural.com/2007/06/blogativista.html>. Acesso em: 24 out. 2008.

- Herdeiro do Caos: blog de ciberativismo. Disponível em: $<$ http://herdeirodocaos.com/>. Acesso em: 24 out. 2008.

c) Sites de Mídia Independente: forma de comunicação alternativa às grandes empresas de mídia que dominam a produção, circulação e divulgação das informações políticas. Apoiando-se no potencial libertário de comunicação da rede, os sites de mídia independente produzem e 
divulgam em seus espaços informações que, na maioria das vezes, não tem visibilidade nos canais de mídia da grande imprensa. Os sites se caracterizam por deixar seus espaços livres para a participação de qualquer usuário que queira divulgar um conteúdo. Caracterizam-se por ter posições críticas frente ao mainstream, atraindo pessoas que compartilham desse ponto de vista, o que limita a sua acessibilidade. Utiliza-se de diferentes formatos, com destaque para vídeos, artigos e chats de discussão. Exemplos:

- Mídia sem Máscaras: site conservador que aborda temas de discussão política. Disponível em: <http://www.midiasemmascara.org/>. Acesso em: 29 out. 2008.

- Central de Mídia Independente: rede de produtores e produtoras de mídia independente. Disponível em: $<$ http://www.midiaindependente.org/>. Acesso em: 29 out. 2008.

- Observatório da Imprensa: site que faz análise crítica da grande mídia. Disponível em: $<$ http://www.observatoriodaimprensa.com.br/>. Acesso em: 29 out. 2008.

d) Lista de e-mail: uso da ferramenta de e-mail para divulgação de ações cívicas, promoção e articulação de ações de grupos de ativismo. Outra forma de ativismo, muito comum na Internet, é o abaixo assinado eletrônico que, por meio de circulação em listas de e-mail, atinge um grande número de usuários, ampliando a participação e repercussão. Alguns abaixo assinados contêm assinaturas de pessoas "famosas", o que aumenta sua visibilidade. Esse tipo de ativismo diminui os custos de participação direta dos envolvidos. Exemplos:

- Em dezembro de 2006, milhares de e-mails travaram os servidores do Congresso, tendo papel preponderante no retrocesso do aumento de $91 \%$ no salário dos parlamentares. Disponível

em: <http://z001.ig.com.br/ig/57/59/933499/blig/taogomespinto/ 2006 52.html\#post 18723043>. Acesso em: 18 fev. 2009.

- Em novembro de 2008, após receber mais de 6.000 e-mails, 0 senador Eduardo Azeredo retirou da pauta o projeto que tentava impor controle à Internet. Disponível em: $<$ http://www1.folha.uol.com.br/folha/informatica/ult124u2098 3.shtml>. Acesso em: 08 fev. 2009.

- Em março de 2005, milhares de e-mails invadiram o site do Congresso (E-Mail: cidadao@camara.gov.br), fazendo com que o deputado Severino Cavalcanti retrocedesse em sua proposta de barrar pesquisas com as células-tronco. Disponível

em: 
<http://www.senado.gov.br/sf/noticia/senamidia/principaisJor nais/verNoticia1.asp?ud $=20050304 \&$ datNoticia $=20050304 \&$ co dNoticia $=147175 \&$ nomeOrgao $=\&$ nomeJornal $=0+$ Globo\&codOr gao=47>. Acesso em: 08 fev. 2009.

e)Hacker: atividade realizada na internet de forma ilícita e anônima. Os ativistas hackers defendem: a livre informação na rede, o acesso ilimitado e total aos computadores, desconfiança em relação às autoridades, luta contra o poder instituído e o "faça você mesmo". Essa prática atrai jovens que dominam o ambiente virtual da internet e utilizam seu conhecimento para promover ações contra alguns símbolos do capitalismo (grandes empresas), instituições públicas, etc. Os hackers caracterizam suas ações por invasão dos domínios das instituições na internet, alterando sua configuração, inclusive, deixando recados. No Brasil, os hackers com atuação política têm pouca visibilidade, dificilmente suas ações ganham repercussão. Por atuarem normalmente à margem da legislação e, também, por serem anônimos, é muito difícil identificar-los. Exemplos:

- The Hackers Brasil: criado pelo hacker Thbrleo. Disponível em: $<$ http://www.thehackersbrasil.blogspot.com/>. Acesso em: 10 fev. 2009.

- Governo federal sobre ataque de hackers (notícia): Disponível em: <http://www.fayerwayer.com.br/2009/01/governofederal-sofre-ataques-hackers/>. Acesso em: 10 fev. 2009.

- Invasão de hackers faz Citibank Brasil recolher cartões (notícia publicada na FSP 08/02/09). Disponível em: $<$ http://www1.folha.uol.com.br/folha/dinheiro/ult91u500646.s html>. Acesso em: 10 fev. 2009.

\subsection{Comunicação Política}

Os dispositivos de comunicação da Internet criam novos espaços de comunicação e interação para a prática política e a comunicação entre os atores políticos e a sociedade. A facilidade, agilidade, praticidade, interatividade e baixo custo, possibilitam que a Internet seja um espaço privilegiado de comunicação, expandindo as possibilidades de interação, assim como criando novas modalidades de mediação. Conforme apontado nas categorias anteriores, a apatia política acaba por ser um fator limitador do uso desses espaços, que ficam restritos, geralmente, a um público de pessoas já interessadas nos assuntos políticos. São exemplos de ação política de comunicação política:

Sites de candidatos: homepages dos candidatos aos cargos públicos eleitorais. No Brasil, de acordo com a atual legislação, os websites dos candidatos somente podem funcionar no período oficial de campanha. Esses sites possuem domínio específico (.can) e são controlados pela Justiça Eleitoral. O uso da Internet nas campanhas eleitorais ainda está 
embrionário; por exemplo, nas eleições da capital paulistana de 2008, a Internet atuou como um extensor das campanhas tradicionais. Sua grande inovação foi a confluência de mídias disponibilizadas nos sites dos candidatos, com vídeos, jingles, banners etc. O uso da web não configurou um novo formato de campanha, mas sim a reprodução, no mundo virtual, do modelo eleitoral, baseado na construção de personagens na disputa pela audiência do eleitorado (Penteado et. al, 2008). O acesso está restrito aos simpatizantes e membros da campanha. Também pode funcionar como ferramenta de articulação e mobilização da militância. Exemplos 5 :

- Soninha: site da candidata nas eleições municipais de São Paulo, em 2008: Disponível em: <www.soninha23.can.br $>$. Acesso em: 23 set. 2008.

- Gilberto Kassab: site do então prefeito, candidato à reeleição em São Paulo, em 2008: Disponível em: <www.kassab25.can.br >. Acesso em: 23 set. 2008.

- Geraldo Alckmin: site do candidato nas eleições municipais de São Paulo, em 2008: Disponível em: <www.geraldo45.can.br $>$. Acesso em: 23 set. 2008.

a) Sites/ blogs de políticos: fora do período eleitoral, os políticos podem criar uma homepage pessoal ou mesmo um blog, para manter um contato permanente com os eleitores e sua base eleitoral. Por ter custo baixo e ser de fácil operação, os sites pessoais acabam por se transformar em mais um canal de comunicação. No Brasil, de forma geral, os sites e blogs de políticos são pouco desenvolvidos, reproduzindo em suas páginas informações gerais e contatos do político, sem saber utilizar as novas ferramentas tecnológicas para criar novos formatos de interação. Exemplos:

- José Dirceu: Blog dentro do site do político e ex-ministro José Dirceu que, atualmente, está com os direitos políticos cassados: Disponível em: <http://www.zedirceu.com.br/>. Acesso em: 23 fev. 2009.

- César Maia: autointitulado "ex-blog" do político César Maia; agora suas notícias são enviadas diretamente por e-mail, a partir de cadastro: Disponível em: <http://cesarmaia.blogspot.com/>. Acesso em: 23 fev. 2009.

- Soninha: Blog da política paulista Soninha: Disponível em: $<$ http://www.gabinetesoninha.blogspot.com/>. Acesso em: 23 fev. 2009.

b) Sites/ blogs de partidos políticos: os partidos políticos também utilizam a Internet como espaço de comunicação política, podendo adotar dois formatos: homepages e blogs, ou mesmo os dois, sendo que diversos

\footnotetext{
5 Por determinação do Tribunal Superior Eleitoral (TSE) - órgão que organiza e fiscaliza as eleições no Brasil, esses sites deveriam e foram retirados do ar, ao término da campanha.
} 
partidos colocam seus blogs dentro dos sites oficiais. Os sites e blogs partidários oferecem aos usuários informações gerais sobre o partido, contato dos seus membros, documentos, propostas, canais de interação, artigos, etc. No Brasil, observa-se que os partidos mais fortes possuem melhores sites, disponibilizando mais e melhores serviços, como é o caso do PT, que tem a "Rádio PT", ou o Partido Democrata, que também tem a "Rádio 25". Exemplos de sites de partidos políticos no Brasil:

- PSDB: Disponível em: <www.psdb.org.br>. Acesso em: 28 out. 2008.

- PT: Disponível em: <www.pt.org.br>. Acesso em: 28 out. 2008.

- PMDB: Disponível em: <www.pmdb.org.br>. Acesso em: 28 out. 2008.

- Blog do Partido Democrata no Brasil: Disponível em: <http://www.blogdemocrata.org.br/>. Acesso em: 28 out. 2008.

\section{Considerações finais}

Uma análise da ação política na Internet brasileira possibilita observar que, apesar de existirem diversas possibilidades de usos e articulações por meio dos dispositivos da web, seu emprego ainda é limitado e pouco criativo, repetindo, por meio eletrônico, antigas formas de atuação política, não sabendo utilizar as potencialidades do meio, principalmente em relação à interatividade.

Por ser uma área nova de pesquisa, existe a necessidade de criar novas ferramentas metodológicas que auxiliem os pesquisadores em suas investigações, assim como suscitar novas questões e desafios. Desta forma, espera-se que a tipologia apresentada acima, consiga contribuir para novas pesquisas na área, assim como para o aperfeiçoamento da mesma, com a inserção de novas modalidades não contempladas no modelo.

Para concluir, ressalta-se a importância da Internet como espaço de atuação que, por sua arquitetura, permite a entrada de novos atores e novas demandas, rompendo os limites tradicionais da política. Não se pretende adotar uma postura otimista e nem pessimista quanto ao uso da internet na promoção de ações políticas. O que pretendeu-se sinalizar, a partir da pesquisa apresentada, é que existe uma tendência para o uso cada vez maior da web, bem como o surgimento de novas práxis, que precisam ser investigadas com mais atenção.

\section{Referências}

CASTELLS, M. A sociedade em rede. São Paulo: Paz e Terra, 1999a. . O poder da identidade. São Paulo: Paz e Terra, 1999b. 
FERNANDES, A. C. G. E-governo: o que já fazem Estados e Municípios. Informe-se BNDES. Secretaria de Assuntos Fiscais, nr 20 - Outubro 2000. Disponível em: $<$ http://federativo.bndes.gov.br/conhecimento/informeSF/inf 20.pdf $>$. Acesso em: 05 fev. 2009.

BARROS FILHO, C.; COUTINHO, M.; SAFATLE, V. O uso das novas mídias na campanha presidencial de 2006. In: LIMA, V. (Org.). A mídia nas eleições de 2006. São Paulo: Fundação Perseu Abramo, 2007.

GOMES, W.; MAIA, R. Comunicação e democracia: problemas \& perspectivas. São Paulo: Paulus, 2008.

GOUVEIA, L. B. Local e-goverment: a governação digital na autarquia. Porto: Sociedade Portuguesa de Inovação, 2004. (Coleção Inovação e governação nas autarquias). Disponível em: $<$ http://www2.spi.pt/inovaut/docs/Manual V.pdf $>$. Acesso em: 02 fev. 2009.

LIMA, V. (Org.). A mídia nas eleições de 2006. São Paulo: Fundação Perseu Abramo, 2007.

LÉVY, P. Cibercultura. São Paulo: Editora 34, 1999.

PENTEADO, C. L. C.; SANTOS, M. B. P.; ARAÚJO, R. P. Internet e política: os blogs nas eleições presidências de 2006. In: ENCONTRO ANUAL DA ANPOCS, 31., 2007. Anais... Caxambu/MG: ANPOCS, out. 2007.

Blog e ação política na Internet. In: ENCONTRO DA ASSOCIAÇÃO BRASILEIRA DE CIÊNCIA POLÍTICA, 6., 2008. Campinas: [s.n.], jul./ago. 2008. Disponível em: < http://201.48.149.88/abcp2008/arquivos/22 7 2008_14_18 53.pdf>.

Acesso em: 04 mar. 2009.

THOMPSON, J. B. O escândalo político. Petrópolis/RJ: Vozes, 2002.

WEBER, M. Economia e sociedade: fundamentos da sociologia compreensiva. Brasília: Editora da UnB; São Paulo: Imprensa Oficial do Estado de São Paulo, 1999. 